moral philosophy. But although Hare is himself interested in first-order issues including medical ethics and has written extensively on them, these essays at least are pitched at a highly abstract level; I do not think it would be easy for the philosophical layman to relate them to medical ethics.

ELIZABETH TELFER Senior Lecturer Department of Philosophy University of Glasgow

\section{People as Patients and Patients as People}

Office of Health Economics, 32 pages, London, $£ 2.50$, Office of Health

Economics, 1989

This booklet is a collection of ten papers delivered to a symposium held to celebrate the 40th Anniversary of the National Health Service. The purpose of the symposium 'was to re-emphasise that the NHS was above all conceived to treat individuals'. Professor Sir David Weatherall talks briefly about 'Hospitals for human beings' and Professor Charles George talks about 'The prescriber's viewpoint'. The contents are somewhat biased towards the pharmaceutical industry: 'A desire to take medicine is perhaps the great feature which distinguishes man from the other animals!'

Professor Teeling Smith, in 'The taxpayer and the patient', reviews some of the well known conflicts which exist in the NHS, with its basic concept of the wealthy well paying for the poor sick. These conflicts include the 'moral hazard' of a service which is being paid for collectively by a large group, and in which each individual tends to make higher demands than he would if he paid for what he was demanding himself.

Then there is the basic conflict of the NHS whereby the taxpayer is financing expensive care for others who are no longer able to pay. Here the healthy taxpayer wants to reduce his outlay, whereas the sick consumer wants the best care regardless of cost. In the NHS, where services are made available regardless of the consumer's ability to pay his immediate cost, Professor Teeling Smith believes that the providers have a special responsibility to ensure that their service is good value for money.
$\mathrm{He}$ also believes that the balance of power between doctors and their patients is shifting (towards the patients) with the increased use of measures of patients' well-being. Professor Weatherall notes that 'unfortunately, there have been few investigations of consumer reactions to hospitals' and calls for more data of this type, because 'despite efforts to maintain patient service, areas of shortfall remain, particularly on the pastoral side of medical care'. These reductions in the standard of patient care, Professor Weatherall believes, are due to the increased throughput in the NHS.

So what is the overall impression after reading these papers about people as patients and patients as people? It is that there have been determined attempts by some to improve the treatment of patients as people (and the Department of Health has now formally recognised the need for this), but other pressures, notably financial, have made it harder to do this and there is still a great deal of improvement that could be made.

But any improvement would be at a cost, either financial or of a reduction in the level of service and we know surprisingly little about patients' preferences about the trade-off between quantity and quality. Until we know more about patients' preferences we can say little about whether we want to concentrate on increasing the quantity or quality of care.

DAVID ALLEN

Senior Lecturer in Health Service Management, North Western Regional Health Authority

\section{Morality: A New Justification of the Moral Rules}

Bernard Gert, 317 pages, Oxford, £27.00, Oxford University Press, 1988

This is the fullest exposition of Gert's moral theory, which first appeared in his book, The Moral Rules, in 1970. It is an objective moral theory applicable to all rational persons, which according to Gert, underpins our common moral system of rules, prohibiting evil acts and promoting ideals which encourage the relief of suffering. From a philosophical standpoint the moral theory has two commendable features. First, it is an objective theory which allows for limited moral disagreement.
For example, when abortion is discussed the scope for rational disagreement is found in the emphasis placed respectively on empirical and non-empirical questions. Typical empirical questions are: 'What effect will allowing abortion have on the way rational persons treat one another?' 'Will allowing abortion result in less concern for human life?' In contrast, non-empirical questions yield discussion on the degree of concern for unborn children.

The second important feature of Gert's moral theory is that it lends itself directly to the resolution of real moral problems. In the early chapters Gert provides a detailed analysis of the central concepts, such as morality, rationality, impartiality, good and evil, moral rules and their justification, virtue and vice, moral judgements, and the relationship between morality and society. He then outlines an approach which he describes as 'morality as impartial rationality'. This is a moral system that would be chosen by an impartial rational observer. Of central importance here is Gert's treatment of the interplay between rationality, impartiality, and specific moral rules which provides the structure for his moral theory. The system of moral rules, which is grounded in Gert's analysis of impartial rationality, underpins imperatives such as do not kill, cause pain, disable, deprive another of freedom or pleasure, do not deceive, do keep promises, obey the law, and do your duty. These are obligatory at all times, and must be distinguished from the moral ideals, such as help the needy, relieve pain, and so on which do not have the same force. For example, punishment may be used to enforce certain moral rules, although it would not be proper to apply it to those who fail to follow a moral ideal.

The final chapter considers ways in which the moral theory can be accepted by any impartial rational person, as a guide to her conduct and others' conduct. The two central topics here are paternalism and euthanasia. As both require justification Gert considers several case studies in which paternalistic behaviour is subjected to the standard of acceptability by an impartial rational person (for example, no impartial rational person would publicly approve of lying to a patient in a situation in which trust is extremely important). Gert's treatment of euthanasia involves an elaborate treatment of the distinctions between active and passive euthanasia which cannot be fully assessed in the space of a 
review, although his suggestion that 'taking a patient who refuses treatment off a respirator counts as passive euthanasia' might be contended.

Anyone with an interest in ethical decision-making would find great value in this book. Gert argues with clarity and precision and should be forgiven for saying so on several occasions. There are shades here, also, of the moral reflections of Hobbes, Rousseau and Hegel, whose views deserve greater prominence in practical ethics. Gert has dealt with complex issues in a manner which is likely to appeal to the intelligent lay reader. 'A book on moral philosophy understandable only by professional moral philosophers', he says, 'is a bad book on moral philosophy'.

DAVID LAMB Senior Lecturer in Philosophy Department of Philosophy Manchester University

\section{Morals, Reason and Animals}

S F Sapontzis, 302 pages, Philadelphia, \$34.95, Temple University Press, 1987

S F Sapontzis, Professor of Philosophy at California State University, describes his book as a 'second-generation contribution' to the philosophical discussion of animal rights, following on from the 'seminal writings' of animal liberation philosophers such as Peter Singer, Bernard Rollin and Tom Regan. The work focuses on what the author regards as the 'pivotal issue' in the animal liberation debate of the past 15 years or so: the moral implications of being or not being 'rational'.

The first part of the book examines the claim that 'reason' is necessary for morality, attempting to refute the argument that only 'rational' beings can be moral agents. In this context, 'rational' is used to refer to normal, adult human intelligence, so that the question is whether only normal, adult humans can be moral agents. (This question has relevance in the animal rights debate since the claim that humans but not animals can be moral agents has been used to justify human exploitation of animals.) Sapontzis takes a 'commonsensical' view of morality, arguing that there is no strict dichotomy, but a continuum between humans and animals. Animals (like retarded or senile humans, human children and other 'marginal cases') behave in ways that achieve moral goods: when such behaviour is intentional and straightforward (ie without ulterior motives) then animals, like human marginal cases, can be considered to be at least 'virtuous agents', if not fully moral agents. Subsequent sections of the book are devoted to an examination of what the author believes to be the logical consequences of this moral continuum.

The second and third parts examine the case for 'liberating' animals, that is, for putting an end to the routine sacrifice of animal interests for human benefit and extending 'moral rights' to animals. Sapontzis argues that this is what we ought (morally) to do, since liberating animals would accomplish three major moral goals: (i) developing our moral character (leading to morality becoming a 'pervasive way of life', with decisions about, for example, what to eat and wear becoming moral decisions); (ii) reducing suffering in life and making life more enjoyable and fulfilling (using 'life' to refer to all sentient beings); and (iii) making the world a 'fairer' place, by ensuring that 'goods, opportunities, punishments and rewards are distributed fairly'. Several arguments opposing animal liberation are analysed and found to be based on the premise that humans but not animals are 'rational'. Sapontzis challenges this opposition, arguing that human rationality is not the oniy source of morality and that animals should be brought into the 'moral community'.

The fourth part of the book then examines some of the likely consequences of our liberating animals. Extending moral rights to animals would not solve the problem of how to treat animals, but would, rather, open the question. Indeed, it is very hard to imagine a world in which animals are not 'exploited' to some extent. Sapontzis recognises this, suggesting that 'liberating animals would have the largest impact on our lives of any moral reform movement to date', but that 'exactly where liberating animals would lead us is something we can only discover as we go along'. He speculates on how such animal liberation would affect our diet (would we be obliged to become vegetarians or even vegans?), research (would there be any circumstances in which we might use animals in research?) and our attitudes towards the general environment.

The questions raised and discussed in this book are both interesting and challenging. The emphasis on the continuum between humans and other animals and the use of extrapolation from our everyday, commonsense morality makes many of the arguments persuasive. There is, however, a lack of empirical information (which the author readily admits). This leads, for example, to the assertion that the 'simple, straightforwardness of [animals'] compassionate, courageous and other such actions is virtually never an issue' being supported mainly byc stories about dogs and porpoises saving drowning humans, by the behaviour of guide-dogs and by examples of animals engaging in parental care. Some more detailed discussion of the relevant ethological and physiological evidence would have been welcome here.

Overall, this book serves to emphasise the complexity of what we call 'morality'. 'Animal liberation' issues are set in the context of the many facets of everyday human moral practice. By using such a 'commonsensical' approach, the author has provided a helpful framework for thinking about our moral obligations towards animals.

JANE A SMITH

Lecturer, Department of Biomedical Science and Biomedical Ethics, The Medical School, University of Birmingham B15 2TT 